\title{
Lesions of the Tegmentomammillary Circuit in the Head Direction System Disrupt the Head Direction Signal in the Anterior Thalamus
}

\author{
Joshua P. Bassett, Matthew L. Tullman, and Jeffrey S. Taube \\ Department of Psychological and Brain Sciences, Center for Cognitive Neuroscience, Dartmouth College, Hanover, New Hampshire 03755
}

\begin{abstract}
Head direction (HD) cells in the rodent limbic system are believed to correspond to a cognitive representation of directional heading in the environment. Lesions of vestibular hair cells disrupt the characteristic firing patterns of HD cells, and thus vestibular afference is a critical contributor to the HD signal. A subcortical pathway that may convey this information includes the dorsal tegmental nucleus of Gudden (DTN) and the lateral mammillary nucleus (LMN). To test the hypothesis that the DTN and LMN are critical components for generating HD cell activity, we made electrolytic lesions of the DTN or LMN in rats and screened for HD cell activity in the anterior thalamus. Directional activity was absent in all animals with complete LMN lesions and in animals with complete DTN lesions, although a few HD cells were isolated in animals with incomplete lesions. Some DTN-lesioned animals contained cells whose firing rates were modulated by angular head velocity. Although cells with bursting patterns of activity have been observed in the anterior dorsal nucleus of the thalamus of animals with disruption of vestibular inputs, this pattern of activity was not observed in either the LMN- or DTN-lesioned animals. The general absence of direction-specific activity in the anterior thalamus of animals with DTN or LMN lesions is consistent with the view that the DTN-LMN circuit is essential for the generation of HD cell activity.
\end{abstract}

Key words: head direction cell; anterodorsal thalamic nucleus; dorsal tegmental nucleus; lateral mammillary nuclei; navigation; place cell

\section{Introduction}

Head direction (HD) cells are neurons located primarily within the limbic system that fire as a function of directional heading in the horizontal plane, independent of the animal's location and behavior (Taube et al., 1990a; Sharp et al., 2001a; Wiener and Taube, 2005; Taube, 2007). Each HD cell is preferentially tuned to a single direction of peak firing (the "preferred firing direction"), from which the firing rate decreases in a near-linear manner as the animal turns its head away from the preferred firing direction. The preferred direction of an HD cell is anchored to the environment such that rotation of prominent landmark cues can induce a corresponding shift in the cell's preferred firing direction (Taube et al., 1990b). The stability of directional tuning can persist for extended periods even in the absence of visual landmarks, such as when an animal locomotes in the dark (Goodridge et al., 1998), but the preferred firing direction will eventually start drifting over time (Knierim et al., 1998). Thus, models of HD cell function describe a confluence of information about selfgenerated (idiothetic) movement and information about stable

\footnotetext{
Received Aug. 31, 2006; revised May 9, 2007; accepted May 28, 2007.

This work was supported by National Institutes of Health Grants NS 053907 and MH 01286 . We thank Jennifer Rilling for technical support. Preliminary reports concerning some of this research were presented at the 28th and 31st annual meetings of the Society for Neuroscience in 1998 and 2001.

Correspondence should be addressed to Jeffrey $S$. Taube, Department of Psychological and Brain Sciences, Dartmouth College, 6207 Moore Hall, Hanover, NH 03755. E-mail: jeffrey.taube@dartmouth.edu.

J. P. Bassett's present address: Department of Physiology and Neuroscience, New York University School of Medicine, New York, NY 10016.

DOI:10.1523/JNEUROSCI.0268-07.2007

Copyright $\odot 2007$ Society for Neuroscience $\quad$ 0270-6474/07/277564-14\$15.00/0
}

features of the environment (allothetic) that can be compared to maintain an ongoing representation of the animal's directional bearing as it moves around. HD cells have been recorded in a number of areas corresponding to structures in the classic Papez circuit: the lateral mammillary nuclei (LMN) (Blair and Sharp, 1998; Stackman and Taube, 1998), the anterior dorsal nucleus of the thalamus (ADN) (Taube, 1995), the postsubiculum (dorsal presubiculum) (Taube et al., 1990), and the retrosplenial (posterior cingulate) cortex (Chen et al., 1994; Cho and Sharp, 2001). The anatomical connections linking these areas suggest the same kind of informational convergence thought necessary for HD cell activity, with an ascending stream of fibers innervating and rising from the LMN to meet corticofugal projections at the thalamus (Fig. 1). Bilateral LMN lesions disrupt directional activity in the ADN (Blair et al., 1999), whereas lesions of other associated areas, including the postsubiculum, hippocampus, or parietal cortex, largely leave direction-specific firing intact in the ADN (Golob and Taube, 1997; Goodridge and Taube, 1997; Calton and Taube, 2001).

Physiological studies have suggested that the origin of the HD signal may lie within the vestibular system, because neurotoxic lesions (both permanent and reversible) of the labyrinth disrupt direction-specific firing in $\mathrm{ADN}$ and postsubicular neurons (Stackman and Taube, 1997; Stackman et al., 2002). Supporting this view, anatomical studies have identified a candidate neural pathway originating in the medial vestibular nuclei (which is innervated prominently by afferents from the horizontal semicircular canals) and projecting to the nucleus prepositus $\rightarrow$ dorsal 


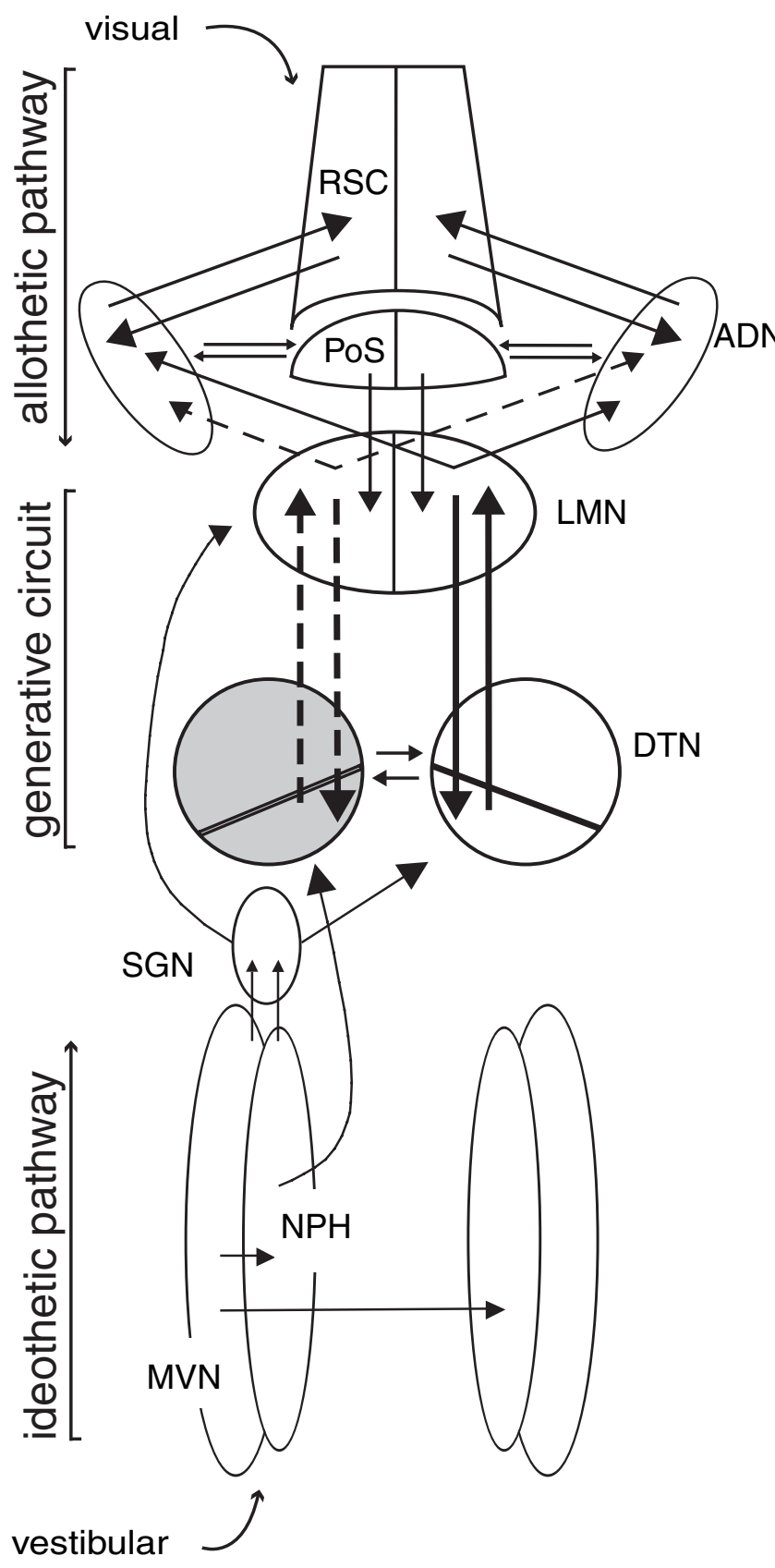

Figure 1. Schematic diagram of HD circuit and model of proposed information flow. The DTN is depicted with a diagonal line transecting it to represent the pars ventralis and pars dorsalis subdivisions of the DTN (Hayakawa and Zyo, 1990). The DTN receives prominent projections from both the nucleus prepositus hypoglossi, ipsilaterally, and the supragenual nucleus, contralaterally (shown on left only). Both are innervated by the medial vestibular nucleus and are therefore likely sources of AHV information to the DTN. These projections to the DTN compose one of what could be multiple idiothetic pathways of information about self-generated movement into the HD system. The ADN is reciprocally connected to the retrosplenial cortex, and to the postsubiculum. These projections may constitute an allothetic pathway through which cortically processed visual, motor, and mnemonic information could enter the HD system. The interconnections of the DTN and LMN may be sufficient to generate the characteristic activity of $H D$ cells, whereas the idiothetic pathway updates that activity from moment to moment based on the animal's movement, and the allothetic pathway relates the representation of directional heading to salient spatial cues from the environment (Sharp et al., 2001a; Taube and Bassett, 2003). In the case of a unilateral lesion (left DTN; gray shading), only information reaching the right DTN from the contralateral supragenual nucleus and ipsilateral nucleus prepositus hypoglossi can reach either ADN via the LMN (lost connections shown as dotted lines). AHV input might still reach the left LMN via a direct projection from the supragenual nucleus (Biazoli et al., 2006). MVN, Medial vestibular nucleus; NPH, nucleus prepositus hypoglossi; PoS, postsubiculum; RSC, retrosplenial cortex; $S G N$, supragenual nucleus. tegmental nucleus (DTN) $\rightarrow \mathrm{LMN} \rightarrow \mathrm{ADN}$ (Fig. 1) (Liu et al., 1984; McCrea and Baker, 1985; Shibata, 1987; Allen and Hopkins, 1989; Graf et al., 2002; Brown et al., 2005). Furthermore, the DTN contains neurons whose firing is modulated by angular head velocity (AHV), direction of head turn, and head direction (Bassett and Taube, 2001; Sharp et al., 2001b). In the studies involving vestibular lesions, Stackman and Taube (1997) reported the emergence of nonrhythmic bursts of activity in ADN, which had the appearance of HD cell firing disconnected from actual head direction, although the authors argued against this interpretation on grounds that no HD cells that were recorded through application of the toxin exhibited burst-like firing after application. In a preliminary report, Muir et al. (2004) also reported bursts of activity in ADN neurons after bilateral occlusion of the semicircular canals. In contrast, Blair et al. (1999) did not report similar activity bursts in ADN after lesions of LMN. Thus, this phenomenon appears to be a result of depriving LMN neurons of ascending vestibular information.

The present study tested the hypothesis that the tegmentomammillary segment of the ascending projection to the HD cell system constitutes a generative circuit by recording neurons in the ADN after lesions of the DTN and LMN. Our goals were twofold: (1) to determine whether lesions of the DTN disrupted direction-specific activity in the ADN and (2) to determine whether lesions in either the DTN or LMN lead to bursts of activity in ADN neurons, similar to those seen in animals with peripheral vestibular lesions. Absence of HD cell activity in the ADN in conjunction with the absence of burst activity after DTN or LMN lesions would support the view that HD cell discharge relies on a subcortical circuit for signal generation that depends on vestibular afference and that the tegmentomammillary circuit is important for establishing the behavior of the neural network (Bassett and Taube, 2005). Alternatively, if burst activity is present after DTN or LMN lesions, this result would indicate that burst activity is a property of the neuronal network within ADN that is generated independently of the tegmentomammillary network.

\section{Materials and Methods}

Subjects. Adult female Long-Evans rats ( $n=25)$, weighing 250-300 g, were housed in shoebox cages in a satellite vivarium on a $12 \mathrm{~h} \mathrm{light/dark}$ cycle and maintained on a food-restricted diet (15-20 g/d), with water available ad libitum. Subjects belonged either to a lesion group (DTN, $n=11$; LMN, $n=5)$ or an unlesioned group $(n=9)$. Lesioned rats in which recording electrodes were later judged to have missed the ADN target are not included here. Data from some rats in the unlesioned group were published in a previous study (Taube, 1995).

Surgery. Rats were anesthetized with sodium pentobarbital $(40 \mathrm{mg} / \mathrm{kg}$, i.p.) and given atropine sulfate $(5 \mathrm{mg} / \mathrm{kg}$ ) to reduce respiratory distress. Lesions were made by passing direct current (model 3500; Stoelting, Wood Dale, IL) through an anodal, stainless-steel insect-pin electrode (Elephant brand, 000 gauge). The electrode was insulated except for 0.5 $\mathrm{mm}$ of the tip, which was scraped bare with a razor blade. Lesions were made bilaterally for both DTN and LMN lesion sites. For DTN lesions, $0.30 \mathrm{~mA}$ current was delivered for $30 \mathrm{~s}$ at the following stereotaxic coordinates: anteroposterior, $-0.20 \mathrm{~mm}$ from interaural line; mediolateral, $\pm 0.30 \mathrm{~mm}$ from midline at bregma; dorsoventral, $+2.40 \mathrm{~mm}$ from interaural line. For LMN lesions, $0.75 \mathrm{~mA}$ current was delivered for $10 \mathrm{~s}$ at the following stereotaxic coordinates: anteroposterior, $-4.5 \mathrm{~mm}$ from bregma; mediolateral, $\pm 1.0 \mathrm{~mm}$ from midline at bregma; dorsoventral, $-8.8 \mathrm{~mm}$ from the dural surface. Animals in the lesioned groups received lesions of either the DTN $(n=11)$ or LMN $(n=5)$ but not both areas together. Coordinates were based on the rat brain atlas by Paxinos and Watson (1998) and modified based on previous histological results.

Chronic recording electrode arrays with microdrives were built using 
methods described by Kubie (1984) and consisted of ten $25-\mu \mathrm{m}$ diameter insulated nichrome wires (California Fine Wire, Grover City, CA) threaded through a stainless-steel cannula and attached to gold contact pins embedded in a nylon connector plug (Augat; Tyco Electronics, Harrisburg, PA). At the time of surgery, electrode wires were trimmed to allow $1.5 \mathrm{~mm}$ to protrude from the tip of the cannula, and the exposed wires were embedded in carbowax (polyethylene glycol) for protection during implantation. The carbowax gradually melted away once in the brain, thus exposing the electrode wires to brain tissue. The target was in all cases the right $\mathrm{ADN}$ using the following stereotaxic coordinates: anteroposterior, $-1.45 \mathrm{~mm}$ from bregma; mediolateral, $+1.3 \mathrm{~mm}$ from midline at bregma; and dorsoventral, $-3.6 \mathrm{~mm}$ from the dural surface. Once the electrode was in place, the microdrive screws were attached with dental cement to the skull surface and to stainless-steel screws placed in the skull. After surgery, animals were given a postoperative analgesic (buprenorphine; $0.02 \mathrm{mg} / \mathrm{kg}$ ) and allowed to recover for $10 \mathrm{~d}$ before commencing cell screening. All animal experimentation was conducted in accordance with the policies described in the Policies on the Use of Animals and Humans in Neuroscience Research (Society for Neuroscience, 1995).

Screening and recording. Rats were screened for unit activity while they foraged for food pellets in a gray cylindrical recording arena. Electrical signals from the electrode wires were passed through a field-effect transistor in a source-follower configuration and then through an overhead commutator (Biela Development, Anaheim, CA). The signals were then amplified ( $\mathrm{P} 5$ series; Grass Instruments, Quincy, MA), bandpass filtered (300-10,000 Hz; $\geq 3$ dB/octave; model PME8; Peavey Electronics, Meridian, MS), and then passed through a series of window discriminators (model DDIS-1; BAK Electronics, Germantown, MD). The resultant signal was then displayed on an oscilloscope (model 2214; Tektronix, Beaverton, OR). The activity from each electrode was monitored while observing the rat's behavior on a video monitor. Two light-emitting diodes (LEDs; one red and one green) attached to the recording cable rotated with the rat's head and were visible to the video camera mounted overhead. The $x, y$ coordinates of the red LED positioned over the rat's snout and the green LED positioned over its back were monitored at $60 \mathrm{~Hz}$ (Ebtronics, Elmont, NY). The relative position of the two LEDs with respect to one another indicated the rat's $\mathrm{HD}$ and its position in the cylinder. Individual electrode channels were monitored relative to a reference electrode, consisting of one of the 10 channels selected for low noise. The electrode array was advanced in increments of $\sim 25-50 \mu \mathrm{m}$ by turning the microdrive screws. In cases in which rats were screened more than once per day, at least $2 \mathrm{~h}$ elapsed in between screening sessions, to allow tissue displaced by the electrode array to stabilize. When the waveform of a cell could be sufficiently isolated from background noise using the window discriminators, the LED coordinates and spike discharges were sampled at $60 \mathrm{~Hz}$ and acquired by a data acquisition interface board (DIO-96; National Instruments, Austin, TX) in a personal computer (Macintosh G4; Apple, Cupertino, CA). Data were stored for subsequent off-line analyses using LabView software programs (National Instruments). Recorded sessions were usually at least $8 \mathrm{~min}$. Cell screening was terminated after a maximum of six complete screw turns of the microdrive, which corresponds to $\sim 2.7 \mathrm{~mm}$ of possible sampling in the dorsalventral plane.

Histology. At the end of screening, all rats were given a lethal dose of sodium pentobarbital $(120 \mathrm{mg} / \mathrm{kg}$, i.p.) and perfused with $0.9 \%$ saline, followed by $10 \%$ formalin in saline solution. Before perfusion, marking lesions $(15 \mu \mathrm{A} ; 20 \mathrm{~s})$ were made on one or two of the electrode wires. After the brains were removed, they were placed in $10 \%$ formalin for at least $24 \mathrm{~h}$. Potassium ferrocyanide was then added to the fixation solution for $24 \mathrm{~h}$ to effect a Prussian blue reaction. The brains were frozen, sectioned at $30 \mu \mathrm{m}$, and stained for Nissl substance with thionin or cresyl violet for microscopic examination and verification of lesion sites and recording electrode tracks. Lesions of the DTN or LMN were verified by identifying areas of gliosis, absence of neurons, and ferrous deposits from the lesioning electrode. The extent of recording electrode tracks through the ADN was visible from the Prussian blue marks at the electrode tips. The position of this ventralmost point relative to the identified boundaries of the $\mathrm{ADN}$ was used to estimate the portion of the screening record that could have conceivably fallen within the ADN, hereafter referred to as the "sampling range." All isolated cells were evaluated for directional and velocity modulation, but only cells recorded inside the $\sim 1 \mathrm{~mm}$ dorsal-ventral sampling range of the ADN were considered part of the experimental sample for the purpose of estimating the incidence rate of directional modulation.

To quantify the amount of damage in four cases in which tissue was preserved in the vicinity of the DTN, we took three digital photomicrographs along the rostral-caudal axis of each lesion site at a caudal, intermediate, and rostral section, corresponding approximately to the diagrams at $-9.8,-9.16$, and $-8.8 \mathrm{~mm}$ from bregma, respectively, in the Paxinos and Watson (1998) rat brain atlas. Each photomicrograph was overlaid with the matching atlas diagram along with a grid scaled at 400 squares $/ \mathrm{mm}^{2}$. Squares inside the DTN area that were empty or contained tissue clearly marked by gliosis were defined as lesioned. Lesioned squares were counted and divided by the total number of squares falling inside the DTN area to give a quantification of lesioned area as a percentage of the whole DTN.

Data analysis. Recorded cells were analyzed for spatial and movement correlates, including HD, AHV, and theta rhythm modulation. The rat's HD was determined from the relative positions of the two LEDs, and its location was defined as a point behind the red (front) LED equal to one-quarter of the distance between the two LEDs. Firing rate as a function of HD was computed by summing the number of spikes that occurred and the time spent in each $6^{\circ}$ angular bin and then dividing the total number of spikes by the time spent in each bin across the entire recording session.

For AHV, HD values were used to construct an HD versus time function that was then smoothed using the following function: $n=\left(n_{t-2}+\right.$ $\left.n_{t-1}+n+n_{t+1}+n_{t+2}\right) / 5$. The first derivative (angular velocity) for each time sample was calculated by defining an episode of five time points centered on that sample and then determining the slope of the best-fit line through those five points. For each cell, firing rate was plotted as a function of AHV using $6 \%$ bin intervals. For each $6 \% \mathrm{~s} \mathrm{AHV} \mathrm{bin,} \mathrm{we}$ calculated values for mean velocity and mean firing rate (number of spikes divided by the number of time samples in each bin). We then plotted a firing rate-by-AHV scattergram for each recording session. Cells were judged to be modulated by AHV if the Pearson's $r$ value of the regression line through the scattergram was significantly different from zero at a significance level greater than $p<0.01$.

To determine whether cell firing was significantly modulated by the animal's directional heading, we performed a Rayleigh test based on the cell's firing rate versus HD tuning curve (Batschelet, 1981). This statistical test first involves computing the mean vector length, $r$, based on the cell's firing over $360^{\circ}$. Mean vector length is calculated by redrawing the tuning curve in polar coordinates and representing each of the firing rates as a vector. The mean vector is then determined using trigonometric functions. Mean vector lengths range between 0 and 1 , with higher values indicating that spike occurrence is clustered around a particular direction. The critical significance level of $r$ is then determined by the number of observations (which was defined as the sum of all firing rates from the 60 directional bins), and if the $r$ value meets this significance level, the distribution is considered to be nonrandom. Cells that exhibited significantly nonrandom distributions were considered directionally tuned, and their directional properties were then analyzed for directional information content, a probabilistic measure of how much a cell's firing can be used to predict the rat's directional heading (Skaggs et al., 1993). Because HD cells have a firing range of $\sim 90^{\circ}$ and often have a small amount of background activity outside the cell's directional firing range, information content for ADN HD cells is not typically $>2.8$ bits (Taube and Muller, 1998). Information content was calculated as follows: IC $=$ $\Sigma p_{i}\left(\lambda_{i} / \lambda\right) \log _{2}\left(\lambda_{i} / \lambda\right)$, where $p_{i}$ is time spent with the head pointing in the $i$ th bin divided by the total time (probability that the head pointed in the $i$ th bin); $\lambda_{i}$ is the mean firing rate of the cell in the $i$ th bin; and $\lambda$ is the overall firing rate of the cell for the entire recording session. Cells that had Rayleigh $r$ values $\geq 0.20$ and directional information content scores $\geq 0.10$ were classified as $\mathrm{HD}$-modulated cells. Two cells that satisfied these criteria were excluded from being classified as directionally modulated cells because their directional modulation was attributed to un- 
Table 1. Summary of histological results and incidence of directional cell activity

\begin{tabular}{|c|c|c|c|c|c|c|c|c|c|}
\hline Rat & DTN lesion & Tissue sparing & $\begin{array}{l}\text { ADN electrode } \\
\text { tracks present }\end{array}$ & $\begin{array}{l}\text { Other damaged } \\
\text { sites }\end{array}$ & HD cells & HD/AHV cells & AHV cells & Theta cells & NDC cells \\
\hline Rat 66 & $100 \%$ & & Yes & mlf, Idtg & & & & 2 & 5 \\
\hline Rat 71 & $100 \%$ & & Yes & mlf, VTN & & & 1 & 2 & \\
\hline Rat 80 & $100 \%$ & & Yes & mlf, Idtg-p, VTN & & & 2 & 9 & 7 \\
\hline Rat 149 & $100 \%$ & & Yes & mlf, VTN, Idtg & & & & 5 & 34 \\
\hline Rat 150 & $100 \%$ & & Yes & mlf, VTN, Idtg & & & & 1 & 12 \\
\hline Rat 153 & $100 \%$ & & Yes & mlf-p, VTN & & & & & 14 \\
\hline Rat 77 & $85 \%$ & Bilateral & Yes & mlf, VTN & 2 & 2 & 4 & 2 & 5 \\
\hline Rat 75 & $82 \%$ & Bilateral & Yes & Idtg & & 2 & 6 & & \\
\hline Rat 69 & $72 \%$ & Left side & Partial & mlf, Idtg, VTN & 1 & & & 2 & 11 \\
\hline Rat 126 & $67 \%$ & Bilateral & Yes & Idtg & 2 & 1 & & 5 & 15 \\
\hline Rat 76 & $50 \%$ & Right side & Yes & mlf-p, VTN-uni & & & & 13 & 10 \\
\hline
\end{tabular}

All recordings were conducted from the right ADN. Idtg, Laterodorsal tegmental nucleus; NDC, nondeterminable correlate; -uni, unilateral lesion; -p, partial lesion.

equal sampling of head directions causing an artifactual peak in the firing rate versus HD plot. This exclusion was justified on grounds that no head directional modulation was observed in a second recording session with more uniform sampling of head directions.

In addition to directional information content, four other parameters to describe the cell's activity were calculated from the firing rate versus HD tuning curve: peak firing rate, preferred firing direction, directional firing range, and background firing rate. Peak firing rate is the firing rate for the $6^{\circ}$ bin in which the cell's firing rate is highest, and the preferred firing direction specifies which bin contains the highest rate. Directional firing range and background firing rate are determined by modeling the firing rate-by-HD function as a triangular function. Best-fit lines are drawn through the points containing the right and left legs of the function. The base of the triangle is bounded at the bottom on either side by points approximating the transition from background to abovebackground firing rates. The directional firing range then is the distance between the two lower boundary points and describes the angular range over which firing is elevated above background rates, and the background rate in turn can be defined as the mean rate over the nondirectional range, bounded by points three directional bins clockwise to the lower boundary of the left leg and three directional bins counterclockwise to the lower boundary of the right leg.

To evaluate stability of the preferred firing direction over days, the firing rate-by-HD curve from one recording session was shifted in $6^{\circ}$ increments until it correlated best (Pearson $r$ ) with the compared session. The number of bins rotated to reach the best correlation corresponded to the shift in preferred firing direction from one session to the other.

We encountered place cells in one animal. The firing rate maps of these cells were analyzed using color-coded firing rate-by-place functions according to the method of Muller et al. (1987). Briefly, the area of the circular recording arena was divided into pixels $(32 \times 32)$, each of which was assigned a color based on the firing rate of the cell when the rat's head fell within the pixel, averaged over the duration of the recording session. Pixels displayed as white indicate no sampling (i.e., the rat did not pass through that pixel). Yellow pixels were sampled spatially without any cell activity recorded (i.e., zero firing rate). Other pixels were assigned colors in descending order from the cell's peak firing rate: purple, blue, green, red, and orange. Starting from the lowest rate/color, pixel color assignments were assigned such that each firing rate range-color assignment placed 0.8 times the total pixels in the next ascending firing rate/color range.

To compare HD cells in DTN-lesioned animals with HD cells in the ADN of intact animals, we drew from data originally reported by Taube (1995), plus previously unreported data from two unlesioned rats. We evaluated the neuronal correlates from these two animals plus seven of the eight animals reported in this previous study, which used surgical and recording techniques and equipment identical to those used in the present experiments (one of the eight animals was removed from the sample because screening ended before the electrode advanced through the ADN and therefore would not provide a reliable index for the fre- quency of encountering specific cell types in our recordings). For a comparison of AHV sensitivity, we selected 10 well isolated HD cells pseudorandomly from among the recorded data from this group. For tests of differences between populations, we used independent two-sample $t$ tests. In the case of incidence rate (HD cells/total isolated cells) per rat, the small sample size in combination with potentially large variance in overall cell yield between rats made an assumption of normality for the two populations uncertain; in this instance, we used corrected $t$ procedures for an assumption of unequal variance.

\section{Results \\ DTN lesions \\ Histology}

Eleven rats received lesions of the DTN. Table 1 summarizes the extent of lesions and the cell yield for each rat, and Figure $2 \mathrm{~A}$ depicts a schematic coronal section at the level of the DTN and illustrates the DTN and surrounding brain areas. Six of 11 cases had complete lesions of the dorsal and ventral divisions of the DTN. Lesions were typically large and extended ventrally and laterally to involve surrounding structures, most commonly the sphenoid nucleus, medial longitudinal fasciculus (mlf), the laterodorsal tegmental nucleus, and the ventral tegmental nucleus. Disruption of the sphenoid nucleus, a small group of cells that lies along the dorsal border of the DTN, occurred in all cases when there was damage to the DTN. In some cases, disruption of the mlf $(n=7)$, ablation of the ventral tegmental nuclei $(n=7)$, or ablation of at least one laterodorsal tegmental nucleus $(n=6)$ was extensive and possibly complete, although there were no instances of complete bilateral lesions of the laterodorsal tegmental nucleus. Damage to these areas was unavoidable because of their close proximity to the DTN. Some animals sustained lesser damage to these same areas: (1) two animals sustained partial damage $(<40 \%)$ to the medial longitudinal fasciculus (Table 1 , rats 76 and 153), (2) one animal had a unilateral lesion of the ventral tegmental nuclei (Table 1, rat 76), and (3) one animal had an incomplete lesion $(<60 \%)$ of the laterodorsal tegmental nucleus (Table 1, rat 80 ). In no case was the supragenual nucleus, which is intimately connected with areas in the HD cell circuitry (Biazoli et al., 2006), involved in the lesion area. Figure $3 A$ shows a representative example of a complete lesion, and Figure 3, $B$ and $C$, shows an example of recording electrode tracks through the $\mathrm{ADN}$ of the same animal. For comparison, a coronal section through the DTN of an unlesioned rat is depicted in Figure 2C.

Of the several surrounding structures involved in the lesions, only the mlf is known to carry vestibular signals, rostrally toward the oculomotor nuclei and the posterior thalamus. There are no 


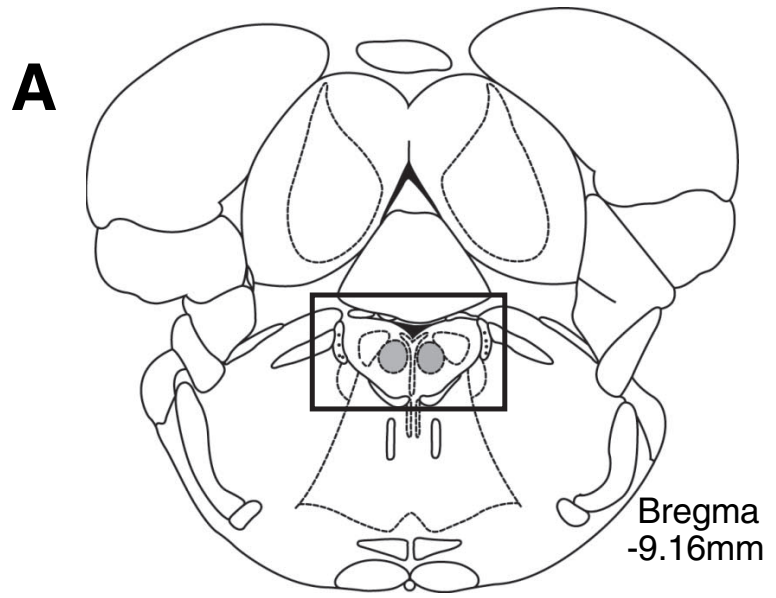

B
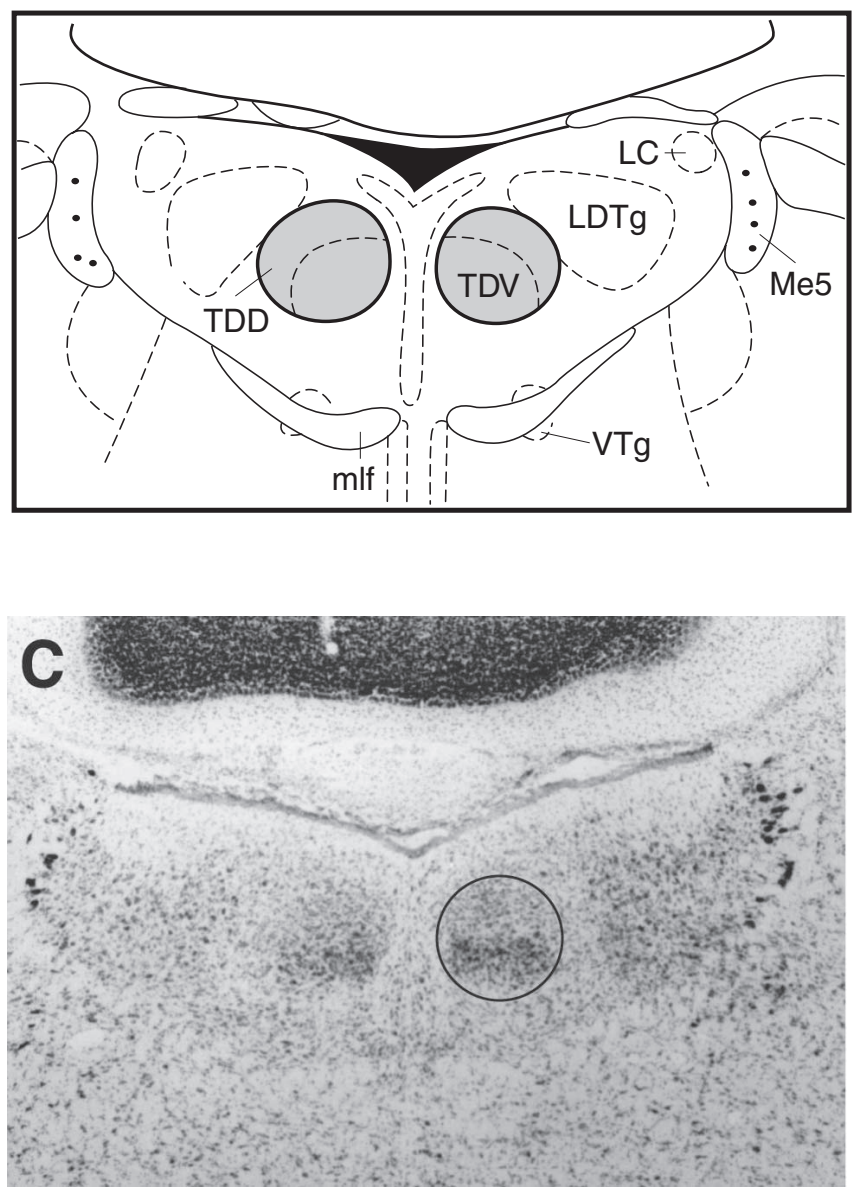

Figure 2. $\boldsymbol{A}$, Location of the DTN. Schematic diagram of a coronal section at $-9.16 \mathrm{~mm}$ posterior to bregma with DTN shaded bilaterally [modified from Paxinos and Watson (1998)]. $\boldsymbol{B}$, Magnified view of the dorsal tegmental area. Enlargement of boxed area in $\boldsymbol{A}$ showing dorsal (TDD) and ventral (TDV) subdivisions of the DTN. Also visible are other structures most likely to be involved in DTN lesions: locus ceruleus (LC), laterodorsal tegmental nucleus (LDTg), mlf, and ventral tegmental nucleus (VTg). Also shown as landmarks are the mesencephalic trigeminal motoneurons (Me5). C, Photomicrograph of section falling approximately within the boxed area in $\boldsymbol{A}$ and $\boldsymbol{B}$ in a control rat showing the DTN (black outline) with its characteristic darkly stained ventral subdivision and the large motor trigeminal neurons visible laterally as landmarks.

known projections to the LMN or ADN by way of the mlf. Nonetheless, lesions of the DTN that also affected the mlf would have interrupted the reciprocating pathway from the LMN to DTN (Fig. 1), which is thought to intermingle with the mlf as it enters the DTN ventrally (Cruce, 1977). Frohardt et al. (2006) described two cases in which the mlf was deliberately interrupted without damaging the DTN and found the animals to be unimpaired on a DTN-dependent spatial task, suggesting functional independence of the DTN and mlf. The adjacent ventral tegmental nucleus of Gudden exhibits a parallel projection pattern to the medial mammillary nucleus, which in turn projects to the anteroventral thalamus. The recent report by Sharp and TurnerWilliams (2005) of AHV and linear velocity correlates in medial mammillary nucleus neurons makes this parallel projection pattern particularly interesting. However, the DTN and ventral tegmental nuclei pathways to the LMN and medial mammillary nuclei, respectively, are well characterized anatomically and are almost perfectly nonoverlapping (Hayakawa and Zyo, 1989). Thus, there is no known pathway by which activity in the ventral tegmental nucleus could readily affect neurons downstream in the ADN. The sphenoid nucleus is a rather obscure structure, both anatomically and functionally, and has no known connections to areas within the HD cell circuitry. In light of these considerations, we argue that the damage specific to the DTN is the most likely cause of our experimental effects.

Five of 11 cases had either incomplete lesions of the DTN $(n=4)$ or a unilateral DTN lesion (rat 76) (Fig. 4A), with the intact DTN clearly identifiable in the hemisphere contralateral to the site of ADN recording. The four partial-lesion cases (rats 69, 75, 77, and 126) showed some spared tissue in the area of the DTN, but more than one-half of the DTN was lesioned in each of these cases. An example of a lesion with some sparing of the DTN is shown in Figure $4 B$.

In 10 of 11 lesioned animals, the electrode array was judged to have passed through the $\mathrm{ADN}$. In the remaining case, the electrode array passed close enough to the $\mathrm{ADN}$ for one or two wires to have passed through the $\mathrm{ADN}$, allowing only partial sampling for HD cells. In one instance, the electrode array passed through the rostral pole of the dorsal hippocampus before advancing through the ADN. Histology from all unlesioned animals showed passage of the electrode array through the ADN.

\section{Neural activity: overview}

A total of 177 cells were isolated within the estimated sampling range of the ADN in the 11 animals with verifiable DTN lesions and electrode paths. Of these cells, 41 cells were classified as thetamodulated, 5 cells were modulated by HD only, 5 cells were modulated by both $\mathrm{HD}$ and $\mathrm{AHV}$, and 13 cells were modulated by AHV only. Importantly, there were no instances of bursting activity as described previously in animals with peripheral vestibular lesions (Stackman and Taube, 1997; Muir et al., 2004). All other isolated cells had nondeterminable correlates. In one rat, five place cells were recorded as the electrode passed through dorsal hippocampus before reaching the ADN. In unlesioned animals, a total of 160 cells were isolated. Of these cells, 73 were HD cells, and the remaining 87 had nondeterminable correlates. The overall incidence of HD cells in lesioned rats (10 of 177; $5.6 \%$ ) was far lower than that in intact animals (73 of 160; 45.6\%). [Note: Although 10 cells were classified as HD cells from the lesion group for these analyses, only four of these cells could truly be considered "classic" HD cells as defined by previous studies and used for the unlesioned group. Were the analyses conducted using only these four classic HD cells for the DTN lesion group, the incidence rate of HD cells in lesioned animals would be even lower.] The number of isolated cells of all types per animal was not significantly different between the lesioned and unlesioned groups (DTN-lesioned rats, $16.1 \pm 3.7$ cells per rat; intact animals, $17.8 \pm 3.6$ cells per animal; $t=-0.366$; $\mathrm{df}=18$; 

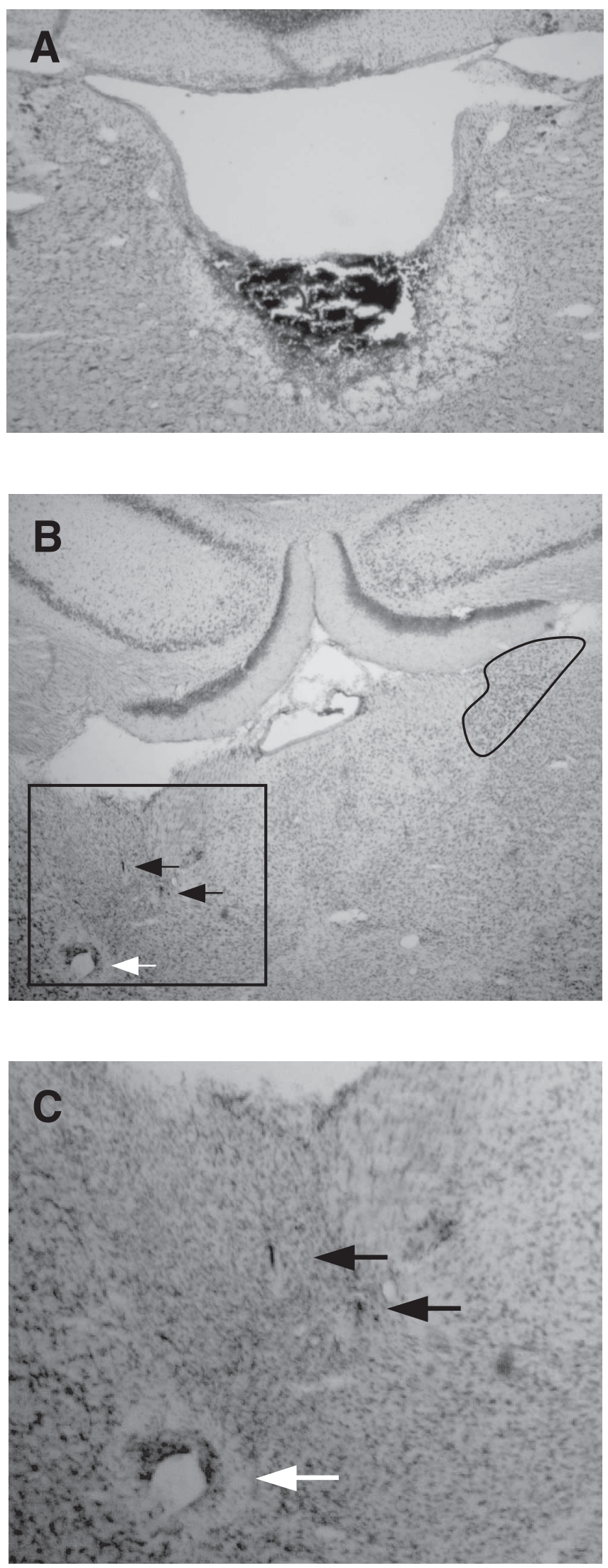

Figure 3. $\quad \boldsymbol{A}$, Complete DTN lesion. A coronal section at approximately $-9.2 \mathrm{~mm}$ posterior to bregma from a lesioned rat shows complete loss of tissue in the immediate vicinity of the DTN and an area of damage that extends ventrally through the border of the tegmental gray area, with the motor trigeminal neurons still visible. $\boldsymbol{B}$, Recording electrode path. Wire tracks through the ADN from the same rat shown in $\boldsymbol{A}$ reflect good sampling of cells within the ADN. Electrode $p>0.5)$ and showed homogeneity of variance. We therefore compared the incidence of HD cells per animal between lesioned and unlesioned groups, to account for any variability that overall cell yield might have on these comparisons. The incidence rate (HD cells/all isolated cells per animal) for DTN-lesioned rats was significantly lower than for unlesioned rats (DTN-lesioned rats, $7.0 \pm 3.2 \%$; unlesioned rats: $46.6 \pm 9.2 \% ; t=4.07 ; \mathrm{df}=9 ; p<$ $0.01)$. Table 2 compares the incidence rate of HD cells between lesioned and unlesioned groups.

\section{Neural activity: HD cells}

The activity of 10 cells was judged to be modulated by HD. These 10 cells were recorded from four of the 11 animals. Importantly, each of these four animals had incomplete lesions. No directionally modulated cells were observed in any of the animals with complete bilateral lesions, nor in one animal with complete unilateral sparing (this latter case is discussed further below). The 10 direction-modulated cells are depicted in Figure 5 and are shown in descending order from highest to lowest directional modulation, according to their associated mean vector $r$ value. The top four cells resemble classic HD cells recorded in unlesioned animals (for detailed description, see Taube, 1995), whereas the remaining six cells are coarsely modulated by HD and in most respects do not resemble HD cells from intact animals. These coarsely tuned cells typically had greater directional firing ranges and higher background firing rates than cells from intact animals. Although the tuning functions for some of these six cells (e.g., cells in Fig. 5, bottom two rows) show very low signal-to-noise ratios and marginally have the appearance of directional modulation, the directional firing range of each cell was stable across multiple recording sessions, indicating that random noise or other artifacts were unlikely contributing to the directional modulation. The four cells that resemble classic HD cells were recorded in three different animals (Table 1), and two of them (rat 126 , cell 3 and rat 77, cell 2) were also modulated by AHV. The six coarsely tuned cells were recorded in three animals, two of which also contained classic HD cells (rats 77 and 126). Three of the six coarsely tuned cells (rat 77, cell 7 and rat 75, cells 1 and 4) were modulated by AHV and, in many respects, resembled AHV-bydirection cells recorded from the DTN (Bassett and Taube, 2001).

The mean background firing rate across all 10 cells was $3.18 \pm$ $0.22 \mathrm{spikes} / \mathrm{s}$ ( $2.61 \pm 0.94$ spikes/s for the four classic HD cells and $3.56 \pm 0.99$ spikes/s for the six coarsely tuned cells). The signal-to-noise ratio was calculated for each cell by dividing the peak firing rate by the background firing rate. As expected, the four well tuned directional cells had a high signal-to-noise ratio (mean, 8.24; range, 5.52-14.17), whereas the six poorly tuned cells had lower signal-to-noise ratios (mean, 3.48; range, $2.94-$ 4.22). The mean directional firing ranges for the four well tuned and six coarsely tuned directional cells were $174.4 \pm 55.9^{\circ}$ and $201.1 \pm 24.1^{\circ}$, respectively. A summary of these values and other properties for these directionally tuned cells is shown in Table 3; comparison values from unlesioned control animals are shown in the right column.

Of the 10 cells that showed direction-specific firing, five cells (two well tuned directional, three coarsely tuned directional) were also modulated by AHV. One cell was modulated only dur-

$\leftarrow$

wire tracks are visible within the ADN (black arrows), and a Prussian blue mark is visible below the ventral extent of the ADN (white arrow). Compression has distorted the ADN and neighboring tissue, but the dark cells of the ADN are still visible. Compare with the right ADN (black outline). $\boldsymbol{C}$, Magnified view of electrode tracks showing boxed area in $\boldsymbol{B}$. 
ing clockwise head turns [asymmetrical firing rate vs AHV plot; type I cells as defined by Duensing and Schaeffer (1958)], but the other four cells had firing rate versus AHV plots that were all symmetrical (type III). On average, AHV sensitivity was less in the ADN of DTN-lesioned animals than in DTN AHV cells, as the mean slope for the linear regression of the firing rate versus AHV plot was 0.03 spikes/degree for ADN cells in DTN-lesioned animals, compared with 0.08 spikes/degree for DTN AHV cells in intact animals, although all AHV sensitivities for these five cells fell within the range reported for DTN cells by Bassett and Taube (2001). As with DTN AHV cells, the firing rate-by-AHV functions for these five HD cells varied in shape between nearly perfectly linear and plateauing at higher velocities, similar to the distinctive scallopshaped functions seen in many DTN AHV cells (Bassett and Taube, 2001). Although Taube and Muller (1998) reported a small but significant AHV correlation $(r=0.12)$ in ADN HD cells, in which firing rates within the cell's preferred direction were slightly higher when the animal turned its head rapidly, scattergram AHV versus firing rate plots were not reported. To make the present results directly comparable with those from nonlesioned animals, we analyzed plots of AHV versus firing rate within the directional firing range of 10 pseudorandomly selected (see Materials and Methods) HD cells recorded previously in the $\mathrm{ADN}$ of intact animals. Comparison between AHV and firing rate functions for $\mathrm{HD}$ cells from intact [slope of best-fit line $=0.044$ spikes/degree] versus lesioned [slope of best-fit line $=0.057$ spikes/ degree] rats reveals a slightly higher AHV sensitivity in lesioned animals, despite a lower mean $r$ value ( 0.26 in lesioned rats vs 0.43 in controls) caused by much lower firing rates. Figure 6 shows a typical firing rate-by-AHV scattergram for an $\mathrm{ADN} H D$ cell in an unlesioned animal compared with a HD cell in a DTN-lesioned animal.

The presence of direction-modulated cells in some lesioned animals, but not in others, requires some consideration; either directional firing in $\mathrm{ADN}$ is possible without the DTN or the activity of these directionally tuned cells is supported by spared tissue. As mentioned above, cells with direction-modulated firing, including both the coarse and typical firing patterns, were identified in four rats that had incomplete lesions. No HD cells were identified in rats with $100 \%$ lesions. We compared the rate of incidence of HD cells (HD cells/total isolated cells) between animals with complete lesions $(n=6)$ and incomplete lesions $(n=5)$. An independent $t$ test showed that the difference in incidence was unlikely to occur by chance $(t=-3.53$; df $=9 ; p<$ $0.01)$. This would appear to justify the conclusion that small amounts of spared tissue in the DTN can support downstream $\mathrm{HD}$ cell activity in the ADN. However, there was one case (rat 76) in which the DTN was fully spared in the right hemisphere and ablated in the left hemisphere. Complete sampling of the right ADN was obtained in this case, and no HD cells were encountered. In another case (rat 69), there was unilateral sparing on the side contralateral to recording, and one HD cell was recorded. These two cases may be explainable by chance, because the incidence of HD cell observation in partially lesioned animals was low $(2.5 \pm 0.6)$, and thus HD cells in rat 76 may simply have been missed. Otherwise, it may be that even small amounts of bilateral or contralateral input from the DTN are sufficient to sustain some characteristic HD cell activity, whereas an imbalanced in-
Table 2. Incidence of HD cells versus non-HD cells in lesioned and unlesioned rats

\begin{tabular}{|c|c|c|c|}
\hline \multicolumn{2}{|c|}{ Lesioned rats $(n=11)$} & \multicolumn{2}{|c|}{ Unlesioned rats $(n=9)$} \\
\hline HD cells/rat & Non-HD cells/rat & HD cells/rat & Non-HD cells/rat \\
\hline 0 & 2 & 14 & 10 \\
\hline 1 & 7 & 7 & 24 \\
\hline 0 & 14 & 1 & 4 \\
\hline 2 & 6 & 8 & 2 \\
\hline 0 & 23 & 1 & 8 \\
\hline 4 & 11 & 14 & 4 \\
\hline 0 & 18 & 7 & 2 \\
\hline 3 & 20 & 5 & 13 \\
\hline 0 & 39 & 16 & 20 \\
\hline 0 & 13 & & \\
\hline 0 & 14 & & \\
\hline Total: 10 & 167 & 73 & 87 \\
\hline Total cells: & 177 & & 160 \\
\hline
\end{tabular}

put from a fully intact nucleus on the side of recording cannot support directional firing. In this light, it may be significant that the DTN is the last point in the ascending circuitry between the vestibular system and the anterior thalamus at which commissural projections could aid compensation after an asymmetric lesion. Crossing fibers link the DTN in each hemisphere, but the DTN-to-LMN projections are entirely ipsilateral (Liu et al., 1984). The LMN projects to the ADN bilaterally, but neither the ADN nor LMN have commissural projections to their contralateral counterparts. Therefore, activity recorded in the ADN can only reflect bilateral vestibular input with both DTNs intact, although Biazoli et al. (2006) have recently reported direct projections from the supragenual nucleus to the LMN, which may constitute a distinct entry for head velocity information into the HD circuit. The anatomical connections described here are summarized in Figure 1.

Even if we conclude that preserved HD activity is attributable to sparing, the capacity for small amounts of tissue to sustain directional firing is notable. One possible explanation for the presence of directional cells in these four DTN-lesioned rats and not others is that the rats with directionally modulated cells were either gradually losing function as a result of incomplete lesions that progressed over time or gradually gaining function through some compensatory mechanism that occurred over time. To address these possibilities, we determined how many days after surgery the electrode would have passed through the estimated sampling range and compared the first, middle, and last day of that period for rats in which no directional cells were found versus rats in which we identified directional cells. This analysis showed that there was no difference in the estimated time after surgery for 

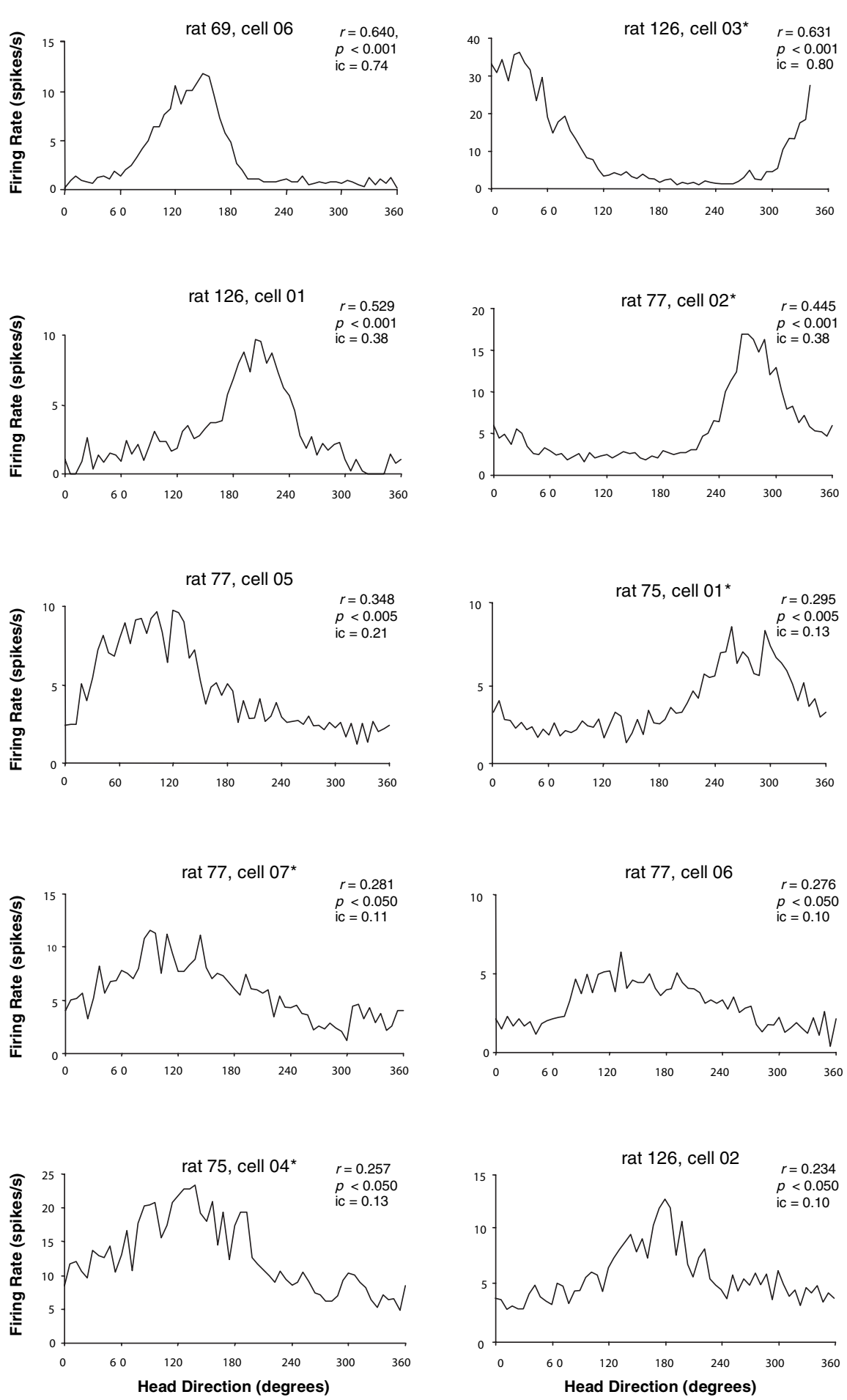

Figure 5. Directional activity in rats with DTN lesions. Firing rate-by-head direction functions are shown for all cells that were classified as directionally modulated according to a Rayleigh test. Mean vector length $(r)$ and level of significance are shown for each cell, and cells are ranked from left to right and top to bottom in order of their value for $r$. Note that the cells with the top four highest mean vector lengths are not noticeably different from normal HD cells and were classified as classic HD cells. The lower six cells were considered coarsely modulated by HD. Asterisks denote cells that were also modulated by AHV.

when cells were recorded in the sampling range between animals in which directional cells were identified and animals in which they were not identified. This result suggests that the directional firing in these animals is not attributable to a gradual loss of function or the emergence of a compensatory mechanism.
Three directional cells remained sufficiently well isolated across multiple days to assess the long-term stability of their preferred firing directions. Two cells were recorded on two separate days, and one cell was recorded on four different days. Shifts of the preferred firing direction across days were generally small $\left(\leq 12^{\circ}\right)$. In nine cases, there were multiple sessions recorded on the same day. Shifts between two sessions recorded on a single day for these nine cells averaged $14.0 \pm 4.1^{\circ}$ (range, $\left.0-42^{\circ}\right)$. This degree of shift varies significantly from shifts between multiple same-day sessions in unlesioned animals, reported by Taube (1995) (mean, $4.7 \pm 1.8^{\circ} ; t=2.34 ; \mathrm{df}=21$; $p<0.05)$. However, the difference between lesioned and unlesioned animals was heightened by one outlier among the DTN-lesioned sample: a shift of $42^{\circ}$. With this outlier removed, the mean shift was $10.5 \pm 2.3^{\circ}$, not significantly different from the intact animals $(t=1.91 ; \mathrm{df}=20$; $p>0.05)$, suggesting that the animal's directional heading, rather than some arbitrary behavior, was indeed modulating the firing rates of these cells.

One directionally modulated cell from rat 126 was tested for its response to rotation of the landmark cue. With the animal removed from the recording arena, the white cue card was rotated $+90^{\circ}$, and the rat was then returned to the arena. After a recording session following the $+90^{\circ}$ rotation, the rat was removed again and the cue card was returned to its original position. On three such trials, the preferred firing direction of the cell shifted in the same direction as the cue card $\left(54,54\right.$, and $\left.36^{\circ}\right)$, although in each case it rotated $<90^{\circ}$ in the corresponding direction. Returning the cue card to its original position led to the cell's preferred firing direction returning to its original orientation. Two directionally modulated cells were similarly evaluated for stability in the dark. After a standard recording session, the cue card was removed, and the lights were turned off. The preferred firing direction for the dark session was then compared with that of the preceding standard session. For five sessions among these two cells, drift of the preferred direction during the dark session was $6^{\circ}$ on average, ranging from 0 to $24^{\circ}$. Although the small sample sizes of cue rotations and dark trials preclude statistical comparison to HD cells in intact animals, both results are qualitatively consistent with cue control and directional stability in intact rats.

Neural activity: AHV cells

Eighteen cells in five rats (including two cells from rats with complete lesions, rats 71 and 80 ) were modulated by AHV in at least 
one direction of turn. Five of these cells were also modulated by the animal's directional heading and were included in the set of cells described above. Thus, the results reported here are confined to the 13 cells that were not modulated by directional heading. Two cells had negative slopes, indicating that increased head velocities correlated with decreased firing rates (Fig. $7 A$ ). The peak firing rate during episodes of little or no movement for these two cells was 4.1 and 6.8 spikes/s, and their firing decreased with movements, making their sensitivity to velocity very low -0.009 and -0.006 spikes/degree. The firing rates of the other 11 cells were positively correlated, and the majority ( 8 of 11) were modulated regardless of the direction of head turn (type III/symmetric) (Fig. 7B). The firing rates of type III cells were all more strongly modulated at lower AHV, giving their firing rate versus AHV functions the distinctive scallop-shaped functions seen in many DTN AHV cells (Bassett and Taube, 2001b). Three were asymmetrically modulated, with AHV sensitivity evident predominantly during counterclockwise head turns (all cells were recorded on the right side, making these type II responses). The firing rate-by-AHV functions for these type II cells were nearly linear in the counterclockwise direction (Fig. 7C), whereas they were modulated only in the low AHV range, or not at all, in the clockwise direction. On average across all cells, AHV sensitivity estimated by linear regression was 0.02 (spikes/s)/(degrees/s), similar to the AHV sensitivities for HD-AHV cells reported above and lower than for DTN AHV cells. Background rates during episodes of little or no movement were $4.62 \pm 0.70$ spikes/s.

AHV cells without modulation by HD have not been reported previously in the ADN (Blair and Sharp, 1995; Taube, 1995). In addition, in recent recordings of ADN cells from intact animals, we have tried without success to identify cells that contain AHV correlates of the type reported in the DTN-lesioned animals (J. S. Taube, unpublished observations). Thus, it is possible that the presence of AHV cells in DTNlesioned animals is a direct result of the experimental lesions. Many DTN neurons exhibit sensitivity to AHV (Bassett and Taube, 2001; Sharp et al., 2001b), as do a subpopulation of LMN neurons (Stackman and Taube, 1998). Thus, an intriguing possibility is that the anomalous AHV sensitivity seen here represents the unmasking of velocity information conveyed to the ADN or LMN from a source not previously proposed (e.g., the supragenual nucleus) (Biazoli et al., 2006) (Fig. 1). The finding of AHV cells in the $\mathrm{ADN}$ is otherwise difficult to reconcile with the premise that the DTN is the sole gateway of AHV information to the HD system.

Neural activity: place cells

In one rat (Table 1, rat 149), the recording electrode passed through the dorsal hippocampus before reaching the ADN. Twelve cells were isolated and recorded. Firing rate-by-place maps for these cells showed that five of them contained identifiable place fields (Fig. 8A). Calton et al. (2003) demonstrated some changes in place cell activity after lesions of the ADN or postsubiculum that were attributed to the loss of directional information conveyed to the hippocampus from these sites. Thus, it was of interest to assess this sample of place cells from a DTNlesioned animal for similar changes, because HD cell activity in the ADN and postsubiculum may be compromised in these animals. The mean spatial firing properties for these five cells were as follows: spatial coherence, $0.21 \pm 0.10$; information content, $1.04 \pm 0.40$; sparsity, $0.24 \pm 0.11$. Values for spatial coherence and information content were well below values reported for CA1 cells from intact animals, although sparsity was similar (Calton et al., 2003).

The five place cells were tested for their response to rotations of landmark cues. While the animal was removed from the recording arena, the white cue card was rotated $\pm 90^{\circ}$, and the rat was then returned to the arena. Place fields that angularly shifted amounts similar to the rotation of the cue card were considered to be controlled by the visual cue. All five place cells were found to be controlled by the visual cue (Fig. $8 \mathrm{~B}$ ), because place fields for 

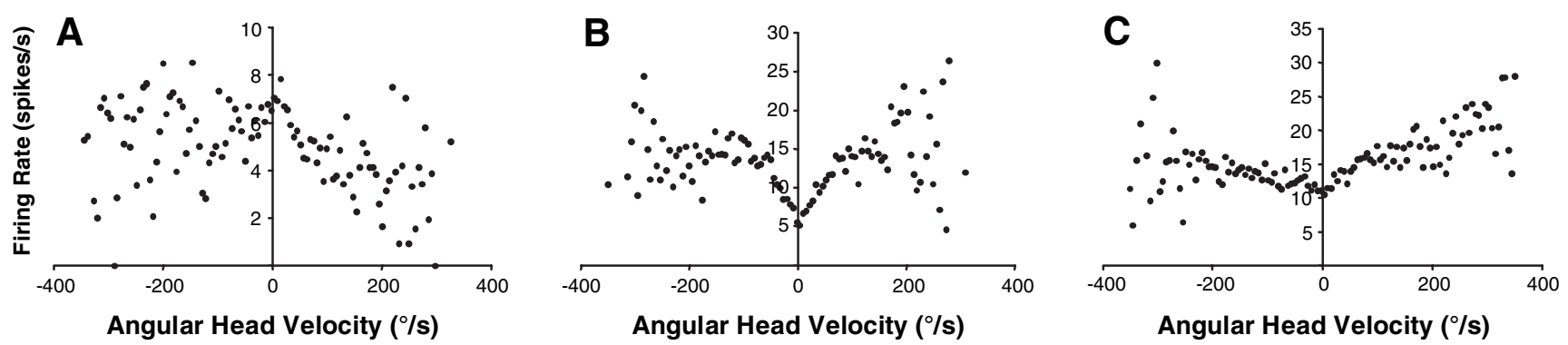

Figure 7. AHV cells in a DTN-lesioned rat. Firing rate-by-AHV functions plotted for ADN cells recorded in DTN-lesioned rats. A, A negatively modulated cell similar to a small number of AHV cells in the DTN and LMN. B, A positively modulated cell that fires with head turns in either direction (type III). Note that firing rates are primarily correlated to AHV at velocities $\leq 100^{\circ} / \mathrm{s}$ in both clockwise and counterclockwise turn directions. C, An asymmetric cell that fires in the direction of contraversive head turn (type II). Negative AHV values (left of 0) refer to clockwise directions; positive AHV values (right of 0 ) refer to counterclockwise directions.
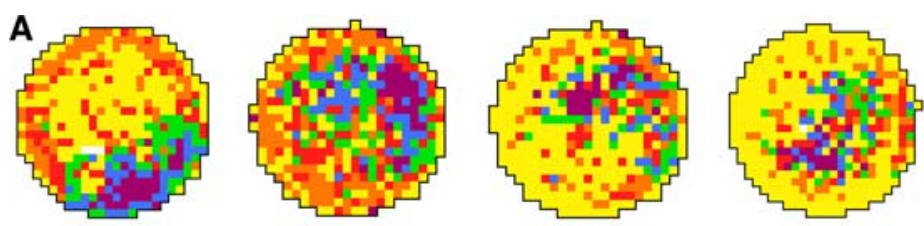

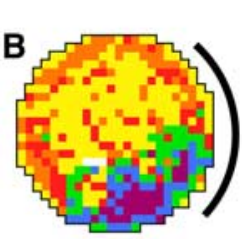

Standard

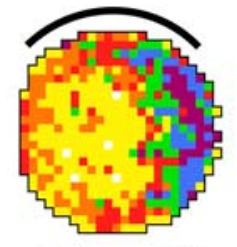

Rotate $+90^{\circ}$

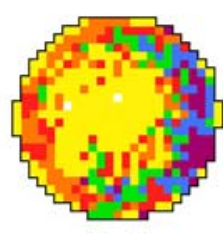

Dark

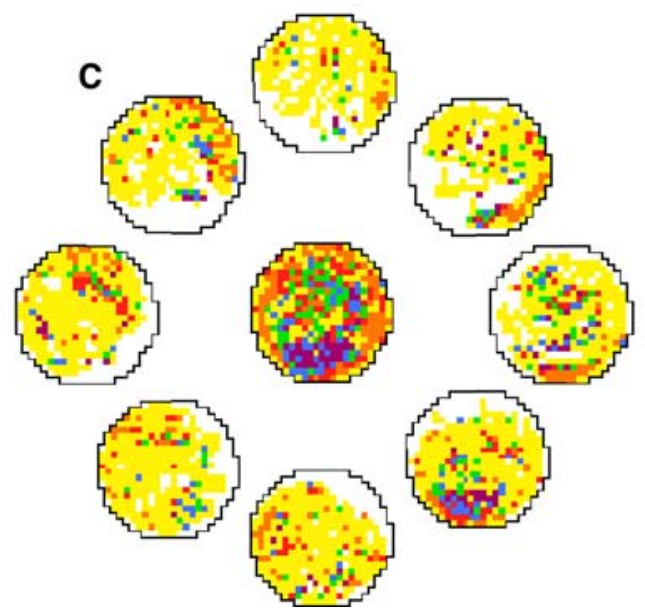

Figure 8. Place cells in a DTN-lesioned rat. $A$, Firing rate-by-place functions plotted for five hippocampal cells recorded in a DTN-lesioned rat (Table 1, rat 149). $\boldsymbol{B}$, A place cell recorded when the white cue card was rotated $+90^{\circ}$. As in intact animals, the place field followed the cue. $C$, Central plot shows firing rate by place for all head directions, as with a standard place cell analysis. The outer eight place-rate maps represent place-modulated activity when the rat's head is pointing in the direction indicated by the plot. For all plots, white pixels indicate that the animal did not visit the location, yellow pixels represent locations visited by the rat but at which the cell did not fire, and other pixels are assigned colors in ascending order according to their firing rate (orange, red, green, blue, and purple), with orange representing the lowest firing rates and purple the highest firing rates. See Materials and Methods for details.

the five cells shifted $54,78,66,78$, and $102^{\circ}$ (mean shift, $75.6 \pm 8.0^{\circ}$ ). Three of the five place cells displayed place-by-direction firing such that place-modulated firing increased when the rat's head was oriented in one direction (Fig. 8C) [compare with Calton et al. (2003),

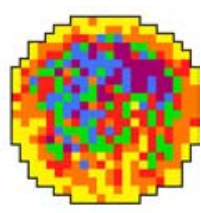

their Fig. 4B]. Although this number of cells represents a small sample, the incidence of place-by-direction firing in an open field is much greater than previously reported for intact animals (Muller et al., 1994) but comparable with that observed in animals with $\mathrm{ADN}$ or postsubicular lesions (Calton et al., 2003).

\section{LMN lesions}

Five cases had complete lesions of the LMN and evidence of recording tracks through the ADN. In some cases, the lesioned area extended into the medial mammillary nuclei, the supramammillary nuclei, or the tuberomammillary nuclei. In no instance did the lesioned area extend beyond the area of the mammillary nuclei. In one case, recording electrodes passed through the dorsal hippocampus and may have penetrated the dorsal aspect of the ADN. Four place cells were recorded from this animal. In the remaining four animals, 41 cells were isolated and recorded. Of these cells, five cells were theta modulated, and the remainder had no determinable behavioral correlate. No cells in any of the five animals exhibited direction- or velocity-modulated firing. In addition, there were no instances of bursting activity similar to that described previously in animals with peripheral vestibular lesions (Stackman and Taube, 1997; Muir et al., 2004). Figure 9 depicts photographs of an LMN lesion along with electrode tracks through the ADN of the same animal.

\section{Discussion}

The major findings were that (1) lesions of the DTN markedly reduced the incidence and robustness of direction-modulated firing in the $\mathrm{ADN}$ and (2) lesions of the LMN completely abolished directionally modulated firing in the ADN. Although the latter finding replicates previous studies (Blair et al., 1999), the DTN lesion results demonstrate for the first time a midbrain site critical for generation of the HD cell signal. Neither lesion 

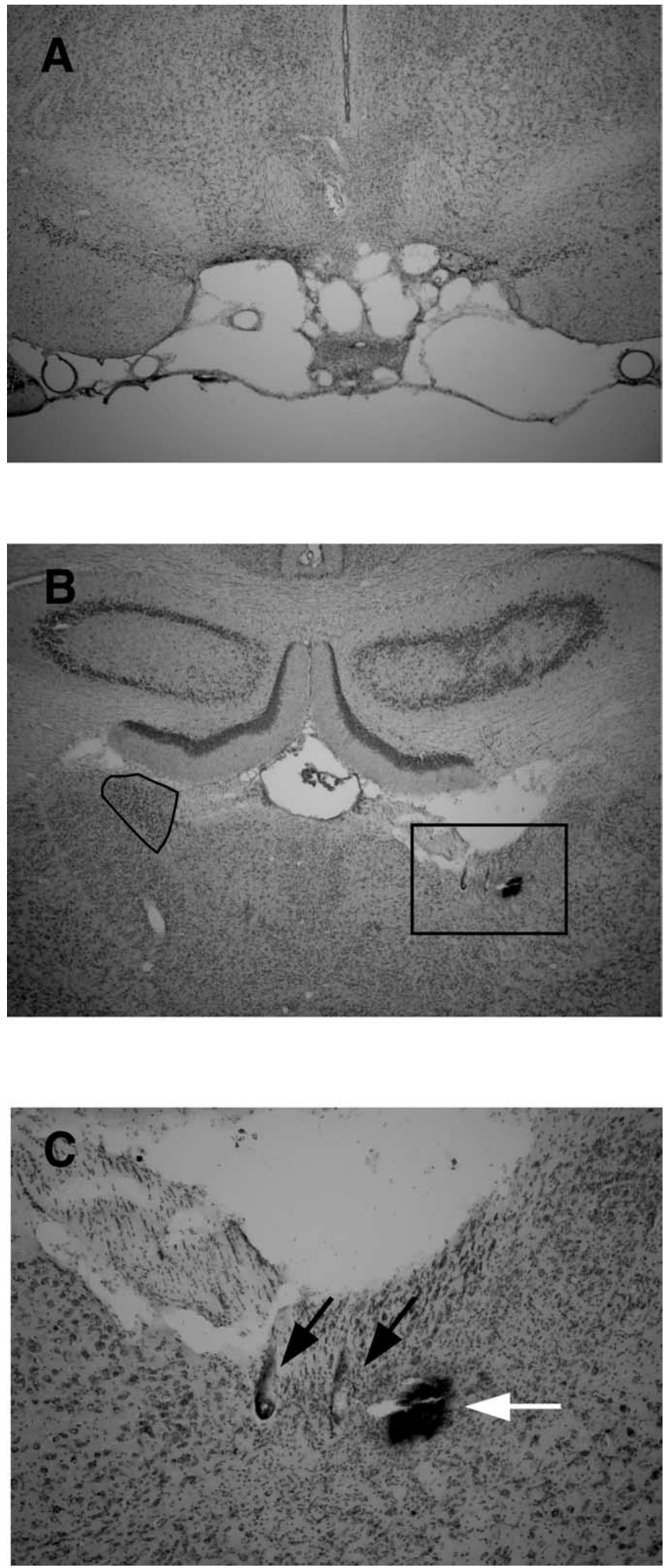

Figure 9. $A$, Complete LMN lesion. A coronal section at approximately $-4.5 \mathrm{~mm}$ posterior to bregma from a lesioned rat shows complete loss of tissue confined to the area of the mammillary nuclei, including both the LMN and medial mammillary nuclei, although a small patch of the medial mammillary nuclei remains visible in the center of the lesioned area. $\boldsymbol{B}$, Recording electrode path. Wire tracks through the ADN from the same rat shown in $\boldsymbol{A}$ reflect good sampling of cells within the ADN. Electrode wire tracks are visible within the ADN and stria medullaris. Compare with the left ADN (black outline). C, Magnified view of electrode tracks showing boxed area in $\boldsymbol{B}$; black arrows indicate electrode tracks, and the white arrow indicates Prussian blue mark. produced bursts of activity resembling those that appeared after peripheral vestibular lesions (Stackman and Taube, 1997).

Precisely where HD cell activity is first generated is unclear. One hypothesis is that the signal arises from information passing between the LMN and DTN and their interconnections, such that rather than the DTN serving as a relay for AHV information to the LMN, it is an integral part of a generative circuit. Anatomical studies showing extensive reciprocal connections between the LMN and DTN are consistent with this notion (Allen and Hopkins, 1990; Hayakawa and Zyo, 1990, 1992). The presence of HD cells in the LMN (Blair et al., 1998; Stackman and Taube, 1998) and possibly a small number of them in the DTN (cf. Bassett and Taube, 2001; Sharp et al., 2001), but not in the major afferent structures to the DTN (nucleus prepositus and interpeduncular nucleus) (Lannou et al., 1984; Sharp et al., 2006), is also consistent with this view. One prediction that follows from this hypothesis is that the effect of interrupting either end of this generative circuit (the LMN or the DTN) should have an equivalent effect of disrupting direction-specific firing downstream in the ADN. With respect to the LMN, bilateral lesions of the LMN do indeed extinguish ADN HD cell activity, with no signs of preserved HD network characteristics.

After lesions of the DTN, the incidence of HD activity in the ADN was far lower than would be expected in an unlesioned animal. We found that 73 of 160 recorded cells in the ADN of nine intact animals displayed direction-specific firing, an incidence of $46 \%$ (mean, $46.6 \%$ per animal), compared with the 10 of 177 or $5.6 \%$ incidence of direction-modulated cells recorded from 11 animals in the present study (mean, $7.0 \%$ per animal). The number of HD cells in lesioned animals is nearly an order of magnitude lower than in unlesioned animals even when variation in cell yield between rats is considered and includes cells that deviate considerably from the usual characteristics of ADN HD cells and would not, for some purposes, be considered HD cells. In six animals with complete lesions and one with a complete unilateral lesion, no direction-modulated firing was encountered. Moreover, all cells that contained direction-specific firing were found in the four animals with incomplete lesions, and even then, the direction-modulated activity was found to be significantly degraded in most of these cells compared with HD cell activity in intact animals. Structures that were often damaged in addition to the DTN were the mlf, laterodorsal tegmental nucleus, and ventral tegmental nucleus (Table 1), and one may argue that it was damage to these structures that resulted in the loss of direction-specific firing. This interpretation is unlikely, however, because if these structures were critical for generating the directional signal, we would expect a complete loss of directional activity in the incompletely lesioned animals. Because some direction-specific activity was observed in the incomplete DTNlesioned animals, despite massive damage to these other areas, it is unlikely that these other areas contribute significantly to the generation of the HD cell signal. Therefore, we can conclude that bilateral lesions of the DTN disrupt direction-specific firing in the ADN and that any remaining direction-modulated activity was most likely supported by spared DTN tissue.

It is noteworthy that the overall number of cells isolated was nearly the same for lesioned versus unlesioned rats. We made no predictions about the effects of DTN lesions on nondirectional activity in the ADN, but one possible outcome might have been quiescence in HD cells after the lesion and a corresponding decrease in overall activity level among cells in the ADN. Instead, there was an increased incidence of nondirectional cells along with the decrease in HD cell incidence, suggesting that HD cells 
may remain active after DTN lesion but fail to exhibit any directional activity.

\section{Preserved HD cell activity}

Although the hypothesis that the HD cell signal is generated in the tegmentomammillary circuit is attractive, two details of the DTN lesion results indicate some caution in accepting this interpretation. First, in one case, no HD cell activity was found although the DTN was completely spared on one side. Second, another case yielded four directional cells despite having $\sim 80 \%$ complete damage, suggesting a surprising degree of robustness.

If $\mathrm{HD}$ cell activity depends on an integration of velocity signals, then an alternate pathway is required for a source of head velocity information into the $\mathrm{DTN} \rightarrow \mathrm{LMN} \rightarrow \mathrm{ADN}$ circuit. Vestibular projections ascend from the vestibular nuclei via the mlf and ascending tract of Deiters to the thalamus (Nagata, 1986). These fibers terminate primarily in the ventral posteromedial nucleus, ventral posterolateral nucleus, and central lateral nucleus of the thalamus. Although it is possible that intrathalamic connections may convey vestibular information to $\mathrm{ADN}$, there are no known anatomical data demonstrating such connections. Furthermore, this pathway depends in part on the mlf, which was disrupted in most of our DTN-lesioned rats. This situation leaves only the ascending tract of Deiters, which runs far laterally to the mlf (Nagata, 1986), as a potential pathway for vestibular information to the thalamus. Alternatively, angular head velocity could be derived from signals resulting from self-initiated movements, either in the form of proprioceptive afference or a motor efference copy. There is evidence that such signals contribute to the HD cell system; Stackman et al. (2003), for instance, found that the preferred firing directions of ADN HD cells shifted when passively transported between two recording chambers but did not shift significantly when the rats walked between the chambers under their own volition. This result suggests a failure of velocityto-displacement integration of motor information in the HD cell system, although vestibular afference was not compromised. Thus, available motor/proprioceptive information may be the source for how angular head velocity information is retained in the $\mathrm{ADN}$, even if vestibular information into the circuit is disrupted by lesions of the DTN.

These pathways and alternative sources of AHV information are all possibilities to account for why some residual HD cell activity was observed after lesions to the DTN. Another possibility is that the remaining directional activity in the $\mathrm{ADN}$ is driven by descending input from an independent circuit in the cerebral cortex. Aside from the $\mathrm{LMN}$, the major projections to $\mathrm{ADN}$ originate in the postsubiculum and retrosplenial cortex, both of which also contain populations of HD cells (Taube et al., 1990a; Cho and Sharp, 2001). Goodridge and Taube (1997) established the dependence of postsubiculum HD cells on an intact ADN, but no similar experiment has been conducted with ADN lesions and retrosplenial cortex recording. Although caloric stimulation evoked activity in the retrosplenial cortex as evidenced by positron emission tomography (Vitte et al., 1996), there is no anatomical evidence for a specific vestibular pathway to the retrosplenial cortex, and it certainly does not follow the familiar thalamocortical route through the ventral posterior thalamic nuclei (van Groen and Wyss, 1990, 2003). Even if the retrosplenial cortex is driving preserved directional activity in $\mathrm{ADN}$, input from the LMN would still appear to be important, because LMN lesions leave no preserved activity. In sum, although a second generative circuit is possible, there is no obvious candidate for an anatomical substrate, and given the overwhelming disruption of direction-specific firing in the completely lesioned animals, we contend that the existence of an alternative pathway is unlikely.

\section{Bursting activity}

There are strong reciprocal connections between the LMN and DTN (Allen and Hopkins, 1990; Hayakawa and Zyo, 1990, 1992). Thus, an important issue concerned with the generation of HD cell activity is to distinguish between two general roles for the DTN. On one hand, the DTN may process AHV information from the vestibular system that updates the HD signal, which is generated at the level of the LMN. In this scenario, the intrinsic characteristics of the HD cell network that allow cells corresponding to one direction to suppress those corresponding to other directions are contained entirely within the LMN, and the role of DTN would be to update the directional heading based on head movement. On the other hand, the generative function may be distributed across the two structures, so that without both structures intact, the stable attractor "ring" architecture, which has been postulated to generate the directional signal (Skaggs et al., 1995; Zhang, 1996), is not viable, and there is no directional signal.

After peripheral vestibular lesions (Stackman and Taube, 1997) or canal occlusions (Muir et al., 2004), bursts of firing were reported in the ADN that were not observed after DTN or LMN lesions. Both reports described intermittent, nonrhythmic bursts of high-frequency firing that arose from a relatively low level of baseline activity. The potential significance of this bursting activity derives from predictions from ring-attractor models, in which an attractor that is uncoupled from its updating inputs (either from head movement or visual cues) could have the appearance of HD cells with shifting preferred firing directions (i.e., intermittent bursts of activity). Stackman and Taube (1997) did not detect burst firing in isolated units that had previously been HD modulated and thus argued against this interpretation of their finding. Even so, because bursting activity is evident after vestibular interventions, but not after either DTN or LMN lesions, it appears to represent a DTN-dependent activation of ADN cells that is present even when modulatory vestibular input is absent. We believe that this finding constitutes further evidence that the architecture for generating the HD signal lies upstream of the thalamus and must include the DTN; if vestibular input is removed, some coherent (if nondirectional) firing activity remains in the form of bursting activity. If the DTN or LMN is removed, no coherent activity remains. The effects of DTN and LMN lesions were not only similar in abolishing directional activity, but they were identical with respect to this anomalous bursting firing pattern. Had this burst pattern of firing been evident after DTN lesions, the implication would be that it corresponds to the activity of LMN neurons deprived of vestibular information conveyed via the DTN. Instead, it follows either that the burst pattern is a reflection of input from the vestibular system in its disturbed state after lesion/occlusion or that both the DTN and LMN are required to bring about this firing pattern in the $\mathrm{ADN}$. In either case, the finding that burst firing is observed after vestibular interventions, but not after DTN or LMN lesions, indicates that these two manipulations have different physiological outcomes on downstream structures.

In summary, destruction of the LMN results in complete absence of HD-modulated activity in the ADN. Destruction of the DTN results in a significant lowering of the incidence of HD cells in the $\mathrm{ADN}$, and the $\mathrm{HD}$ cells that remain are often atypically modulated by AHV. We conclude that HD cell activity in many parts of the brain depends ultimately on a tegmentomammillary 
generative circuit that transforms angular velocity signals into HD signals. Thus, we would predict that lesions to structures afferent to the DTN-LMN circuit would disrupt directionspecific firing throughout the brain. In contrast, lesions to structures efferent to this circuit might disrupt directional activity in areas downstream of the lesion site but could leave directionspecific firing intact in other brain areas (Sharp et al., 2001a; Taube, 2007).

\section{References}

Allen GV, Hopkins DA (1989) Mamillary body in the rat: topography and synaptology of projections from the subicular complex, prefrontal cortex, and midbrain tegmentum. J Comp Neurol 286:311-336.

Allen GV, Hopkins DA (1990) Topography and synaptology of mamillary body projections to the mesencephalon and pons in the rat. J Comp Neurol 301:214-231.

Bassett JP, Taube JS (2001) Neural correlates for angular head velocity in the rat dorsal tegmental nucleus. J Neurosci 21:5740-5751.

Bassett JP, Taube JS (2005) Head direction signal generation: ascending and descending information streams. In: Head direction cells and the neural mechanisms of spatial orientation (Wiener SI, Taube JS, eds), pp 83-109. Cambridge, MA: MIT.

Batschelet E (1981) Circular statistics in biology. New York: Academic.

Biazoli Jr CE, Goto M, Campos AM, Canteras NS (2006) The supragenual nucleus: a putative relay station for ascending vestibular signs to head direction cells. Brain Res 1094:138-148.

Blair HT, Sharp PE (1995) Anticipatory head direction signals in anterior thalamus: evidence for a thalamocortical circuit that integrates angular head motion to compute head direction. J Neurosci 15: $6260-6270$.

Blair HT, Cho J, Sharp PE (1998) Role of the lateral mammillary nucleus in the rat head direction circuit: a combined single unit recording and lesion study. Neuron 21:1387-1397.

Blair HT, Cho J, Sharp PE (1999) The anterior thalamic head-direction signal is abolished by bilateral but not unilateral lesions of the lateral mammillary nucleus. J Neurosci 19:6673-6683.

Brown JE, Card JP, Yates BJ (2005) Polysynaptic pathways from the vestibular nuclei to the lateral mammillary nucleus of the rat: substrates for vestibular input to head direction cells. Exp Brain Res 161:47-61.

Calton JL, Taube JS (2001) Head direction cell activity following bilateral lesions of posterior parietal cortex. Soc Neurosci Abstr 27:537.30.

Calton JL, Stackman RW, Goodridge JP, Archey WB, Dudchenko PA, Taube JS (2003) Hippocampal place cell instability after lesions of the head direction cell network. J Neurosci 23:9719-9731.

Chen LL, Lin LH, Green EJ, Barnes CA, McNaughton BL (1994) Headdirection cells in the rat posterior cortex. I. Anatomical distribution and behavioral modulation. Exp Brain Res 101:8-23.

Cho J, Sharp PE (2001) Head direction, place, and movement correlates for cells in the rat retrosplenial cortex. Behav Neurosci 115:3-25.

Cruce JA (1977) An autoradiographic study of the descending connections of the mammillary nuclei of the rat. J Comp Neurol 176:631-644.

Duensing F, Schaeffer KP (1958) Die aktivateinzelner neuronen im bereich der vestibular-ischkerne bei horizontalbeschleunigungen unter besonderer beruchsichtigun des vestibulararen nystagmus. Arch Psych Nervenkr 198:225-252.

Frohardt RJ, Bassett JP, Taube JS (2006) Path integration and lesions within the head direction cell circuit: comparison between the roles of the anterodorsal thalamus and dorsal tegmental nucleus. Behav Neurosci 120: 135-149.

Golob EJ, Taube JS (1997) Head direction cells and episodic spatial information in rats without a hippocampus. Proc Natl Acad Sci 94:76457650.

Goodridge JP, Taube JS (1997) Interaction between postsubiculum and anterior thalamus in the generation of head direction cell activity. J Neurosci 17:9315-9330.

Goodridge JP, Dudchenko PA, Worboys KA, Golob EJ, Taube JS (1998) Cue control and head direction cells. Behav Neurosci 112:749-761.

Graf W, Gerrits N, Yatim-Dhiba N, Ugolini G (2002) Mapping the occulomotor system: the power of transneuronal labeling with rabies virus. Eur J Neurosci 15:1557-1562.
Hayakawa T, Zyo K (1989) Retrograde double-labeling study of the mammillothalamic and the mammillotegmental projections in the rat. J Comp Neurol 284:1-11.

Hayakawa T, Zyo K (1990) Fine structure of the lateral mammillary projection to the dorsal tegmental nucleus of Gudden in the rat. J Comp Neurol 298:224-236.

Hayakawa T, Zyo K (1992) Ultrastructural study of ascending projections to the lateral mammillary nucleus of the rat. Anat Embryol (Berl) 185:547-557.

Knierim JJ, Kudrimoti HS, McNaughton BL (1998) Interactions between idiothetic cues and external landmarks in the control of place cells and head direction cells. J Neurophysiol 80:425-446.

Kubie JL (1984) A driveable bundle of microwires for collecting single-unit data from freely-moving rats. Physiol Behav 32:115-118.

Lannou J, Cazin L, Precht W, Le Taillanter M (1984) Responses of prepositus hypoglossi neurons to optokinetic and vestibular stimulations in the rat. Brain Res 301:39-45.

Liu R, Chang L, Wickern G (1984) The dorsal tegmental nucleus: an axoplasmic transport study. Brain Res 310:123-132.

McCrea RA, Baker R (1985) Anatomical connections of the nucleus prepositus of the cat. J Comp Neurol 237:377-407.

Muir GM, Carey JP, Hirvonen TP, Minor LB, Taube JS (2004) Head direction cell activity is unstable following plugging of the semicircular canals in the freely-moving chinchilla. Soc Neurosci Abstr 30:868.11.

Muller RU, Kubie JL, Ranck Jr JB (1987) Spatial firing patterns of hippocampal complex-spike cells in a fixed environment. J Neurosci 7:1935-1950.

Muller RU, Bostock E, Taube JS, Kubie JL (1994) On the directional firing properties of hippocampal place cells. J Neurosci 14:7235-7251.

Nagata S (1986) The vestibulothalamic connections in the rat: a morphological analysis using wheat germ agglutinin-horseradish peroxidase. Brain Res 376:57-70.

Paxinos G, Watson C (1998) The rat brain in stereotaxic coordinates, Ed 4. San Diego: Academic.

Sharp PE, Turner-Williams S (2005) Movement-related correlates of singlecell activity in the medial mammillary nucleus of the rat during a pelletchasing task. J Neurophysiol 94:1920-1927.

Sharp PE, Blair HT, Cho J (2001a) The anatomical and computational basis of the rat head-direction cell signal. Trends Neurosci 24:289-294.

Sharp PE, Tinkelman A, Cho J (2001b) Angular velocity and head direction signals recorded from the dorsal tegmental nucleus of Gudden in the rat: implications for path integration in the head direction cell circuit. Behav Neurosci 115:571-588.

Sharp PE, Turner-Williams S, Tuttle S (2006) Movement-related correlates of single cell activity in the interpeduncular nucleus and habenula of the rat during a pellet-chasing task. Behav Brain Res 166:55-70.

Shibata H (1987) Ascending projection to the mammillary nuclei in the rat: a study using retrograde and anterograde transport of wheat germ agglutinin conjugate to horseradish peroxidase. J Comp Neurol 264:205-215.

Skaggs WE, McNaughton BL, Gothard KM, Markus EJ (1993) An information-theoretic approach to deciphering the hippocampal code. Adv Neural Inform Proc Sys 5:1030-1037.

Skaggs WE, Knierim JJ, Kudrimoti HS, McNaughton BL (1995) A model of the neural basis of the rat's sense of direction. In: Advances in neural information processing systems, Vol 7 (Tesauro G, Touretzky DS, Leen TK, eds), pp 173-180. Cambridge, MA: MIT.

Stackman RW, Taube JS (1997) Firing properties of head direction cells in rat anterior thalamic neurons: dependence upon vestibular input. J Neurosci 17:4349-4358.

Stackman RW, Taube JS (1998) Firing properties of rat lateral mammillary single units: head direction, head pitch, and angular head velocity. J Neurosci 18:9020-9037.

Stackman RW, Clark AS, Taube JS (2002) Hippocampal spatial representations require vestibular input. Hippocampus 12:291-303.

Stackman RW, Golob EJ, Bassett JP, Taube JS (2003) Passive transport disrupts directional path integration by rat head direction cells. J Neurophysiol 90:2862-2874.

Taube JS (1995) Head direction cells recorded in the anterior thalamic nuclei of freely moving rats. J Neurosci 15:70-86. 
Taube JS (2007) The head direction signal: origins and sensory-motor integration. Annu Rev Neurosci, in press.

Taube JS, Bassett JP (2003) Persistent neural activity in head direction cells. Cereb Cortex 13:1162-1172.

Taube JS, Muller RU (1998) Comparisons of head direction cell activity in the postsubiculum and anterior thalamus of freely moving rats. Hippocampus 8:87-108.

Taube JS, Muller RU, Ranck Jr JB (1990a) Head-direction cells recorded from the postsubiculum in freely moving rats. I. Description and quantitative analysis. J Neurosci 10:420-435.

Taube JS, Muller RU, Ranck Jr JB (1990b) Head-direction cells recorded from the postsubiculum in freely moving rats. II. Effects of environmental manipulations. J Neurosci 10:436-447. van Groen T, Wyss JM (1990) Connections of the retrosplenial granular a cortex in the rat. J Comp Neurol 300:593-606.

van Groen T, Wyss JM (2003) Connections of the retrosplenial granular b cortex in the rat. J Comp Neurol 463:249-263.

Vitte E, Derosier C, Caritu Y, Berthoz A, Hasboun D, Soulie D (1996) Activation of the hippocampal formation by vestibular stimulation: a functional magnetic resonance imaging study. Exp Brain Res 112:523-526.

Wiener SI, Taube JS (2005) Head direction cells and the neural mechanisms of spatial orientation. Cambridge, MA: MIT.

Zhang K (1996) Representation of spatial orientation by the intrinsic dynamics of the head direction cell ensemble: a theory. J Neurosci 16:21122226. 